\title{
Rural Women's Representation and Participation in Local Governance in the Masvingo and Mashonaland Central Provinces of Zimbabwe
}

\author{
Jeffrey Kurebwa \\ Department of Peace and Governance, Bindura University of Science Education, P. Bag 1020, Bindura, \\ Zimbabwe
}

\begin{abstract}
This paper focuses on the study of women's participation in local governance with specific reference to rural women in the Masvingo and Mashonaland Central provinces of Zimbabwe. Taking the status quo pertaining to the representation of women in local governance, it identifies the barriers towards the development and advancement of women towards senior administrative and political positions; and it also argues for increased representation and participation of women in local governance. The presence of more women is required if the local governance system is to become inclusive of the diversity of the people it represents, especially women. Furthermore, change is more likely to occur when elected women are supported by the presence of more women at the most senior administrative levels in the local governance system. Through their knowledge and understanding of the construction of power relations at the local level, rural women have creatively managed to produce, reproduce and use alternative strategies which are based on their sexuality and traditional gender roles in challenging and transforming gender inequality at the local level and in improving the quality of rural women. The purposes of the study were to identify and explore the key challenges that rural women face in their representation and participation in local governance and reflect on the initiatives that are being undertaken by the government and various organizations in facilitating the full representation and participation of rural women in local governance. A qualitative research method was used in the study. Empirical data was gathered through interviews in the Masvingo and Mashonaland Central provinces of Zimbabwe. The research findings indicated that rural women face a number of constraints in getting access to and participating in local governance. These constraints include; cultural beliefs; violence against women; lack of resources; lack of mutual support among women. Among others, the study recommends the creation of an enabling environment for women's political empowerment and capacity-building programmes.
\end{abstract}

\section{Introduction And Backgroud}

Women's voice in Zimbabwe has grown in strength due to a significant increase in the number of women's organisations. During the pre-independence period, a number of organisations were established with active support from urban elite groups, but none was able to mobilise public opinion and rights, in part because these organisations did not reach into the rural areas where the majority of the population lived and in part because the objectives of these organisations in furthering women's issues were not unified (Khan, 1993). At the time of independence in 1980 there were a dozen women's organisations, primarily based in urban areas and oriented towards welfare-related activities. Women's formations, beginning in the late 1970s and into the 1980s, began asserting a new frame of politics that highlighted the multiple dimensions of power and oppression, including contestation in politics and self-determination alongside class, nationalist and anti-imperialist struggles.

By the early 1990s many changes had taken place. First, the number of these organisations had grown rapidly during this period. Second, these organisations shifted their emphasis from welfare to development, stressing the importance of enabling poor women to obtain access to credit, employment, income, literacy, healthcare and family planning. Third, these organisations had begun to expand their activities into rural areas and were mobilising rural women on a regular basis (Makanje, 2004).

The renewed attention to women's organising can be linked to a growing realisation of its unique location within social movements, in particular the critical and potent role it can play in political and social projects, in revitalising social movements, and in deepening democracy in society at large. There are at least two related reasons behind such a role:

First, the women's movement forwards an encompassing conception of political engagement that spans "the personal and the political", which confronts the question of power in both the reproductive and the productive spheres, underscoring the need to intervene in private and public arenas of political contention (Marana, 2007:12). 
Second, the women's movement(s) cuts across and straddles various social movements, political blocs, sector-based organisations and ideological formations. As such, the women's movement is able to capture a wide range of issues and struggles, which makes it well placed, theoretically speaking, to generate a sharper, more textured view of power inequalities and present a more comprehensive, holistic and inclusive framing of progressive political projects (Maranan, 2007).

In this respect, the women's movement(s) has the potential to become a pivotal force for democratic deepening and transformative politics, which will be significant not only within social movements but also, more importantly, in society at large. However, alongside such recognition is a need for a critical reflection on, for example, the kinds of political projects that can be agreed on.

At independence, women's participation in the liberation struggle was acknowledged and rewarded through the passing of various pieces of legislation such as the Legal Age of Majority Act - making black women majors under the law and able to vote and contest for elections for the first time; the Sex Disqualification Act - allowing women to hold public office; and the Equal Pay Act (Ziyambi, 1997). These pieces of legislation were passed by the government partly as a result of pressure from women leaders within the ruling party Zimbabwe African National Union Patriotic Front (ZANU-PF) and partly out of the government's own volition. The changes were driven by the need to mobilise rural women to participate in post-independence development and reconstruction. Though post-independence Zimbabwe witnessed legal reforms that pushed through liberal feminist reforms, the changes were structured to exclude women in the rural areas. The result was that patriarchal discourse, practice and ideology reinforced male dominance in these areas (Gaidzanwa, 1994; Kesby, 1999; Paradza, 2010).

Fundamentally changing the status quo and promoting women's rights were a secondary and very small part of this state 'benevolence' (Makanje, 2004:120). At independence women were for the first time in the history of the country officially recognised as an oppressed group and as such were the target of a conscious government policy to change their situation. The government wanted to transform the status of women so that they could assume their rightful position in society and work alongside their male counterparts in the development of the nation. As soon as it became a member of the United Nations and the African Union, the government ratified a number of international and regional instruments and protocols that had a strong bearing on the status of women (Tichagwa, 1998). The idea was to eliminate all customary, social, economic and legal constraints that inhibited women's full participation in the development of the country.

By the mid-1990s there were 25 registered women's organisations independently addressing various aspects of women's lives in urban and rural areas. Despite initial atomisation, these organisations have come to constitute a network as each developed an operational niche or sector complementing the work of sister organisations in formal and informal struggles for gender justice (IJR, 2005). Although the organisations reflected a conceptual unevenness in the understanding and articulation of gender as a political struggle, with some overtly feminist in orientation and others more mainstream or conservative in their approach, they all played a role in re-defining the private and public sphere in the process of demanding full rights for women (Makanje, 2004).

A landmark development in projecting the gender question was the founding of a women's coalition on constitutional and governance issues in 1999. It was an influential voice in the constitutional reform movement. The Women's Coalition consisted of women activists, academics, researchers and representatives from about 30 women's and human rights organisations. It stood as a broad lobby and advocacy front that pressed for constitutional reform which would protect women's political, social, economic and cultural rights (IJR, 2005). However, the pronounced shift to state authoritarianism in 2000 resulted in repressive measures that weakened the Women's Coalition. In particular, political violence from 2000, a raft of authoritarian legislations on political and civic life, deterred progress in the advocacy and lobbying role of groups that constituted the Coalition (EISA, 2007).

There are still major gaps or structural constraints that women's organisations have to negotiate and overcome. The two levels of their struggle have been described as crucial. The first is the level of a feminist consciousness, where women have fought a war against patriarchy since the pre-independence period, through a critique of discriminatory legislations and demands for committed measures to increase women's political representation. The second is at the oppositional level, where some women's groups in alliance with other Civil Society Organizations (CSOs) and opposition political parties have challenged the state and legitimacy of the ruling party ZANU-PF and the lack of a free participatory environment (Chiroro, 2005).

This paper focuses on women's participation in local governance in Zimbabwe with reference to the Masvingo and Mashonaland central provinces. Arguments for women's participation in local governance are advanced and thereafter, the research methodology and the findings of the study are presented. 


\section{Arguments For Women's Participation In Local Governance}

Women's representation and participation in politics at the local government level is a key driver for their empowerment. It is at the local government level where political parties are able to recruit their members and identify potential candidates who can later move on to contest at the national level (Panday, 2008). It is also at the local level where there is a higher probability of direct impact of women in politics because of its proximity to the community. Global evidence about women's actual presence in rural local governments and their potential impact is still very scarce (Irwin, 2009). Although information about the number of women in urban local governments and national parliaments is collected and systematised as a key indicator for assessing progress on the advancement of women's political rights, research available at the global and local level on women's presence in rural local governance is virtually non-existent (UCLG, 2004). While women's participation in politics, at both national and local government levels, is a matter of gender equality.

Opare (2005) argues that the ability of any group of people or their chosen representatives to participate in decisions affecting their lives not only puts them in a position to contribute ideas but also provides them with the tools and options for reshaping the course, direction, and outcome of specific programmes and activities which will determine their future. It is therefore critical to engage women in decision-making processes within the communities where they reside and obtain their livelihoods.

Other assertions often encountered are that local politics is about issues that concern women's daily lives such as water, waste disposal, health and other social services. This implies that participation in local government is an extension of women's involvement in the civic issues facing their communities (Jayal, 2005). Other scholars also suggest that it is easier for women given their household constraints and childcare responsibilities, to participate in public life at a level more proximate to them (Evertzen, 2001). Such assertions may imply that national-level politics is about issues more distant from and perhaps incomprehensible to women. However, practical concerns are undoubtedly important as such arguments seem to convey the ideological flavour of patriarchy.

A more convincing argument for representation and participation of women in local governance is rooted in the conviction that unless all sections of society, whether women, racial or religious minorities and other disadvantaged groups are represented in legislative bodies, their interests will not be articulated and therefore will suffer from policy neglect (Chowdhury, 1994; Panday, 2008). Democratic history and practice clearly demonstrate that even democratic institutions, based as they are on the principle of one-person-one vote, are blind to cultural and gender differences. Therefore, they do not spontaneously provide any guarantee for effective representation of women's interests, or indeed those of other marginalised or excluded groups (Jayal, 2005). For there to be tangible policy outcomes that take into account the special needs and interests of women, there is need for effective representation, which in turn may involve making a case for special arrangements, such as quotas for women's participation. It is because of these imperfections in the way in which representative institutions actually work, that the case has been made for replacing the "politics of ideas", rooted in the context of rival political visions, by the "politics of presence" effectuated through safeguarded quotas (Phillips, 1995:123; Jayal, 2005:46).

In view of the foregoing argument for the participation of women in local governance, this study investigated the challenges faced by women with regard to their participation in local governance with particular attention paid to the rural women. The study therefore seeks to address the question: What are the challenges faced by rural women in participating in local governance?

\section{Research Design And Methodology}

Zimbabwe has 10 provinces and 61 Rural District Councils (RDCs). The study covered two provinces of Masvingo and Mashonaland Central with a total of 15 RDCs and 410 wards. 105 wards out of the 410 wards in the two provinces were sampled using the purposive sampling technique. The sample of the study was comprised of 250 respondents. They comprised of 15 District Administrators (DAs), 105 Ward Councillors, six officials from NGOs at provincial level, four party district chairpersons of the two political parties dominant in the two provinces, the Zimbabwe African National Union Patriotic Front (ZANU-PF) and the Movement for Democratic Change (MDC), and 120 rural women. Male councillors were included to establish whether their views on women's representation and participation are of any divergence from the views of women and if so in what particular aspects. The inclusion of men in the sample was important to understand the impact that women have on men in local government structures and also to understand how they view changes that are likely to take place, if any, as a result of the inclusion of women in this sphere of government (Morna and Tolmay, 2010). The intention of sampling women ward councillors was to establish how such women perceive the process of getting elected into local councils.

Qualitative data was used in this study. Qualitative research methodology was chosen because the investigation involved an in-depth study of entities such as legal, institutional, policy and decentralisation aspects of representation and participation which are the main features of local governance. Data collection was 
undertaken through interviews. The interviews were controlled to the extent that each participant covered the specific areas which were being explored, yet still sufficiently open and flexible to allow a cooperative approach, with each participant being able to speak in his or her own words. The research enlisted the services of two research assistants who underwent training before going on a pilot scheme by collecting data from the field. This pre-testing of the interview schedules helped to determine the competence of the research assistants, as well as the validity and reliability of research instruments.

\section{Discussion Of Findings}

The study found that the challenges faced by women, especially rural ones, regarding their representation and participation in local governance in Zimbabwe include political violence, stereotypes which are based on culture and socialization, lack of resources, heavy workload emanating from domestic responsibilities, lack of education and information, personal barriers, institutional factors, and lack of mutual support among women.

\section{Political Violence Against Women}

Throughout the interviews with ward councillors, District Administrators (DAs), party chairpersons and rural women, the issue of political violence arose as a barrier to rural women getting into local politics. The findings of the study showed that $96 \%$ of ward councillors and $97 \%$ of rural women ranked political violence as the biggest barrier to the participation of rural women in local politics. It was observed that violence against women in Zimbabwe takes mainly the following forms: physical, psychological and forced isolation and the undermining of a woman's self-esteem, sexual violence and economic violence, through which women may be denied access to work, income and maintenance. The respondents indicated that Zimbabwean politics was fraught with violence, especially during election periods, and unfortunately women were seen as easy targets.

Some respondents indicated that in the 2008 post-election violence, rural women were systematically raped and tortured to ensure their isolation from the communities in which they had been politically active. One female Movement for Democratic Change- Tsvangirai (MDC-T) supporter in Masvingo province mentioned that women drop out of election races because of the fear of being beaten and violated. She indicated that she knew of incidents where people were abducted and tortured. She said that women felt that standing for elections is not worth the sacrifice they have to make. Research participants concurred that the violent nature of Zimbabwean politics and the country's political instability during the period 2000 to 2008 was a deterrent to women standing for elections as councillors, MPs and Senators. Female councillors and representatives of women's organisations indicated that women are the ones who promote unity and harmony in communities.

Pre-election political environments in Zimbabwe have been tense, hostile and volatile and are characterised by electoral campaigns marred by high levels of intimidation, violence, and displacement of people, abductions and loss of life (PAP, 2008). Manifestations of violence included torture, rape, beatings by youth militia invading villages, burning down houses, and setting up torture camps in rural and urban areas. Interviews with ward councillors, rural women and women's organisations highlighted the issue of political violence both as a barrier to women getting into local politics as well as to their ability to participate effectively once they were elected (Sachikonye, 2011).

\section{Culture and Socialisation}

Culture and socialisation was ranked as the second barrier to the participation of women in local governance: $94.1 \%$ of the rural women and $86.3 \%$ of female councillors interviewed mentioned the patriarchal mindset that they encountered in society and in political parties as the key challenge in performing their role as public representatives effectively. They said that they were not treated equally by male councillors and were not taken seriously by some council authorities. Female councillors complained that male councillors brought their patriarchal attitudes from home to the council. Male domination in the councils and in its functioning makes it a patriarchal site where women have to continue to fight their way by resisting public patriarchy on a daily basis.

The cultural barriers shaped by patriarchal political discourse become vital structural factors in determining the level of women's participation in politics. Women have to negotiate their entry into and claim public space according to the discursive, cultural and material opportunities available to them in a given cultural and societal context. Although gender role ideology is not static - rather it is in flux due to its constant intersection with ever-changing economic, social and political systems - women continue to be defined as private beings in dominant cultural discourses, which results in creating structural barriers to women's entry into politics (Bratton, 1989).

\section{Lack Of Resources}

The third most important factor that limits the respect and legitimacy in decision-making of rural women is their lack of economic means: $97 \%$ of rural women and $80.4 \%$ of ward councillors cited lack of 
resources as a factor which limits them in participating in local governance. Women's economic activities and the resources they may generate would strengthen women in several ways. First, economic resources may free the necessary time for discussion and participation on local decision-making. Second, they empower women, giving them the sense they can accomplish things. Third, they raise the stature of women within their communities, both with men and with young people. Not having economic interests precludes a range of interests that would compel women to set certain priorities, support particular local investment, and take an interest in national policies.

Most of the ward councillors cited inadequate resources as hampering their operations and development plans in the individual wards. The female councillors pointed out that if a councillor is not well known and does not have influence within their political parties, they struggle to access sufficient resources to implement development projects. For those with political muscle, resources are forthcoming. The Councillors also agreed that their allowances were too low and in most cases they use their own resources to do council business. The three most important resources, according to Medoff (1986) are money, people and time. He indicated that candidates with more money in an election campaign are more likely to win. He argues that women candidates never raise as much money as their male counterparts, so women need to develop other campaign strategies such as making time for campaigning and networking to reduce this disadvantage.

\section{Domestic Responsibilities}

While the survey showed that only a few rural women $(52.9 \%)$ and female councillors $(70.6 \%)$ rated this as a barrier, possibly because they have been socialised not to think of their domestic chores as a barrier, women have the burden of domestic or private responsibilities which they have to balance with their political and public duties. In addition many of them have other full-time jobs so that they can support their families, resulting in their having to juggle their time between politics, work and home. Lack of support from husbands and families exacerbate this situation. Female councillors interviewed (74.5\%) mentioned that they were fully supported by their families in contesting as councillors. However, they mentioned the continued pressure they had to face to shoulder their domestic responsibilities in the same way as before. They said they had competing demands on their time due to their triple productive, reproductive and community managerial responsibilities. They were left with little time to participate in politics. Many reported that they suffer from extreme stress in managing these triple roles as there is no support available from their families, political parties, their council or the state.

\section{Lack Of Education}

In Zimbabwe there is no educational requirement to become a councillor. The Councillors' Handbook (2009: 42) states: "It does not matter if you are male or female, old or young, educated or unschooled, left or right wing, you should aim to be the best councillor you can be." The biographical data of respondents showed that $60.3 \%$ of rural women had secondary education while $60 \%$ of female councillors had attained the same qualification. However, education is still seen as a key barrier to women's effective participation by rural women, councillors and party chairpersons. Ward Councillors (54.9\%) and rural women (52.6\%) rated lack of education as a key barrier. Women's organisations felt that women's lack of education was a key contributing factor to their lack of confidence. They also said that women's participation could be enhanced through education starting at a young age. Others said education was important because it would mean that female councillors would start to raise women's issues in their council.

\section{Personal Barriers}

As the findings of the study reveal, $24 \%$ of the female councillors, compared with $7.8 \%$ male, had been elected for the first-time. They lack confidence, relevant council experience and basic knowledge and skill in council work. Similarly, they indicated that they lack sufficient gender understanding on how to represent women's interests. They also lack advocacy skills to promote women specific issues. As a result of all this, they are not able to make effective alliances, networks and linkages within and outside councils with stakeholders.

The findings of the study revealed that the level of confidence and capacity-building needs of female councillors vary according to their political background and their exposure to the public and to political life. The needs of female councillors and those of their male counterparts were different. Similarly female councillors elected as chairpersons of council committees had specific training needs. As mentioned earlier, $74.5 \%$ of the ward councillors said they had contested as councillors with the consent of their families. However, they felt constrained due to competing demands from their families and their council responsibilities. Issues of mobility, lack of independent sources of income and lack of social capital as women, limit the scope of their political work. At the personal level, female councillors faced barriers mainly due to demographic factors such as education, employment and age and family factors that include their triple roles and family support. These 
factors affect female councillors' self-confidence and motivation and limit their representation and participation in local governance.

\section{Lack Of Information}

One important constraint on interest of women in their capability to make decisions is their lack of information. The informational constraints fall in three categories:

a) Limited channels of communication and limited content regarding sources of information. Illiteracy is one impediment because it precludes the receipt of information from newspapers, magazines, and other printed material;

b) Poverty is another, constraining access to television and radios; and

c) The last constraint is time. One issue related to information channels for women is the reliance on radio and the possibility that radio broadcasts are not sufficient for informing rural women: $42.6 \%$ of rural women and $40 \%$ of female councillors indicated that radio was their major source of information.

\section{Lack Of Mutual Support Among Women}

While it is undeniable that women bear the brunt of gender inequality because of patriarchy and other factors, it is also true that they are their own detractors. One of the research findings is that the reason for low women's participation in politics is the 'pull-her down syndrome' among Zimbabwean women: 50.9\% of the ward councillors and $39.8 \%$ of rural women indicated this barrier under 'other' factors. One female MP stressed that during campaigns women were difficult to work with as compared with men. She indicated that women were constantly trying to outdo and out-maneuver each other instead of working together.

\section{Institutional Factors}

Government laws were an important factor in the selection of women into decision-making bodies, according to $30.9 \%$ of rural women and $42.1 \%$ of ward councillors. Institutional factors refer to the laws and various formal arrangements that guide the mechanics of governance and political participation. Institutional factors that limit representative participation include the type of electoral system and how women's representation is outlined in a country's or political party's constitution or legal framework. This includes the rules and procedures through which candidates are selected or votes are cast in an election, and in turn helps to determine the extent to which local decision-making bodies are genuinely democratic, inclusive and gender-sensitive. Several elements of the institutional design have a major impact on women's opportunities to stand for election and to be elected (Matland, 2005).

\section{Conclusion And Recommendations}

The research findings indicated that rural women in Zimbabwe face two problems in particular: underrepresentation and low participation compared to women in urban councils and men in formal political and economic institutions and formal and informal rural institutions. The factors commonly identified as barriers to women's participation include political violence, gender stereotypes and outright discrimination, personal obstacles such as lack of confidence, culturally prescribed domestic roles, lack of education, lack of financial and socio-economic capital, winner-take-all electoral systems, and political institutions that are not conducive to balancing family and public life.

Representation is an important indicator of the social and political status of women. Generally, women tend to be under-represented in positions closely identified with power and predominate in administrative and service occupations as indicated by the findings. Adequate representation of women in local governance is crucial to ensure that local governments are more representative of the communities they serve.

Female councillors have a strategic role to play in ensuring that RDCs respond to rural women's needs. Female councillors are well placed to represent and address the diverse needs of rural women within their wards and ensure that RDCs are sensitive to women's issues and that male councillors take them seriously. Increased participation of rural women in RDCs will foster a change in attitudes towards women's involvement in public life and expand women's opportunities beyond those traditionally assigned to women.

Participation of women in local governance should be enhanced in all three essential areas: as voters, policy-makers and as members of decision-making bodies. There is need for policies that involve empowering Rural District Councils (RDCs) and communities to develop strategies that combine the empowerment of communities and rural women. In order to be able to identify the needs of the community and to best promote social and economic development, RDCs need the input of their constituents to be able to best identify those areas that need addressing. RDCs must encourage the involvement of the community and community organisations in local governance. This will help in developing capacity of women and institutions for effective political participation and contribute to the improved economic and social outcomes in the form of poverty reduction, sustainable development and more balanced gender relations in Zimbabwe. 
The dominant ideology in organisations should not be male-biased because under such circumstances transformation is unlikely to take place. Male-dominated hierarchical power often purposefully excludes women's participation or devalues their contributions, creating a disabling environment for women's advancement. These intangible informal institutional values, norms, structures, and processes are difficult to recognise and often constitute a greater barrier than formal rules. For women to benefit, leadership needs to become actively involved in the social transformation of patriarchal norms and values and must include women's perspectives on and participation in the transformation process. Women in leadership positions likewise need to challenge the rules and not to play by them.

There is need for collaboration with local universities, research institutions, academia, media and women's movement in undertaking in-depth research on gender issues, challenges and coping strategies including the issues of political representation and participation and documentation of the research findings for a database of local knowledge on the subject. Such indigenous knowledge can be very useful for designing, formulating and implementing gender-sensitive policies and evaluating their impact on participation. It can also be used for identifying training needs and developing training material, besides sharing with women the contributions of their female colleagues, successful practices and lessons for improved participation.

Fostering a more inclusive and transformative type of politics means creating a more generalised political participation. Political participation is therefore a continuing process. It is necessary to create an environment that will facilitate the election, appointment or promotion of a sufficient number of women to decision-making positions. The goal of a sufficient number refers more to a situation where it is no longer remarkable for women to be put in positions of power, rather than a specific target of say $20 \%$ or $30 \%$. Yet this environment is not simply for producing women leaders but also to develop a new and active citizenry among women. A strong political will on the part of government and the leadership of political parties, business, trade and labour unions, academia and other social institutions is critical in achieving an environment conducive to promoting women's political participation.

The mass media can be used to make women aware of their contribution and to expose gender inequalities. Furthermore, media work is also important to combat negative stereotypes. National institutions in many countries implement broad-based public information campaigns concerning the decentralisation process. Differing starting points of women and men, and between different groups of women and men, must be taken into consideration when developing strategies for public information and education. This can be done through assistance to public information campaigns through local radio stations, theatre groups or trained multipliers can be an effective tool to demonstrate to women the relevance of decentralisation for their daily lives. Relevant issues to address are the roles and functions of local authorities as well as central government, opportunities for women to participate in local government development and decision-making processes, and the rights and responsibilities of citizens.

\section{References}

[1]. Bratton, M (1989). 'The Politics of Government-NGO Relations in Africa', World Development, 17: 569-587.

[2]. Chiroro, B (2005). 'Persistent Inequalities: Women and Electoral Politics in Zimbabwe's Elections in 2005', Journal of African Elections, 4 (2): 91-106.

[3]. Chowdhury, N (1994). 'Women in Politics', Empowerment: A Journal of Women for Women (1): 21-42.

[4]. Electoral Institute of Southern Africa (EISA) (2007). 'Consolidating Democratic Governance in Southern Africa: Zimbabwe'. EIS A Research Report, No. 30. EISA.

[5]. Evertzen, A (2001). Gender and Local Governance. Amsterdam: Netherlands Development Organisation (SNV), Netherlands.

[6]. Gaidzanwa, R (2004). 'Gender, Women and Electoral Politics in Zimbabwe'. EISA Research Report No 8. Johannesburg.

[7]. IJR (2005). The Prospects of Democracy in Zimbabwe. Cape Town: IJR.

[8]. Irwin, R (2009). 'Dancing in the Lion's Den: Women Leaders in Local Government'. Unpublished Doctoral Thesis, Southern Cross University, Australia.

[9]. Jayal, G. N (2005). From Representation to Participation: Women in Local Government, Nehru University, New Delhi.

[10]. Khan, N. A (1993). 'Towards an understanding of 'Participation': The Conceptual Labyrinth Revisited', Administrative Change, XX (1-2): 106-120.

[11]. Kesby, M (1999). 'Locating and Dislocating Gender in Rural Zimbabwe: The Making of Space and Texturing of Bodies', Gender Place and Culture, $6(1): 27-47$

[12]. Makanje, R.; Shaba, L. M. and Win, E. J (2004). Linking Rights and Participation: Zimbabwe Country Study, Institute of Development Studies: Sussex.

[13]. Maranan, F (2007). 'Reflection and Insights on the Status and Directions of Women's Political Participation: Re-imagining Women's Movements and Struggles in Conversations with Women' A collaborative project between the Women's Education, Development, Productivity \& Research Organization (WEDPRO) and the Institute for Popular Democracy (IPD). Phillipines: WEDPRO.

[14]. Matland, R. E (2005) 'Enhancing Women's Political Participation: Legislative Recruitment and Electoral Systems', in Women in Parliament: Beyond Numbers, $2^{\text {nd }}$ edition, A. Karam and J. Ballington (eds.), Stockholm, Sweden, IDEA Publishing.

[15]. Medoff, M. H (1986). 'Determinants of the Political Participation of Women' in Public Choice 48: 245-253. Dordrecht: Martinus Nijhoff Publishers.

[16]. Morna, C. L. and Tolmay, S (eds.) (2010). At the Coal-face: Gender and Local Government in Zimbabwe. Gender Links: South Africa. 
[17]. Opare, S (2005). 'Engaging Women in Community Decision-making Processes in Rural Ghana: Problems and Prospects. Development in Practice 15: 90-99.

[18]. Panday, K. P (2008). 'Representation without Participation: Quotas for Women in Bangladesh', International Political Science Review, 29: 489.

[19]. Pan African Parliament (PAP) (2008). 'The Pan African Parliament Election Observation Mission to the Presidential Run-off and Parliamentary By-elections in Zimbabwe', Interim Statement. 29 June 2008, Harare.

[20]. Paradza, G. G. M (2010). 'Single Women, Land, and Livelihood Vulnerability in a Communal Area in Zimbabwe', Unpublished Doctoral Thesis, Wageningen University: Netherlands.

[21]. Phillips, A (1995). The Politics of Presence. Oxford: Clarendon Press.

[22]. Sachikonye, L (2011). When a State Turns on its Citizens: 60 Years of Institutionalised Violence and Political Culture, Jacana Media (Pty) Ltd, South Africa.

[23]. Tichagwa, W (1998). Beyond Inequalities: Women in Zimbabwe. Harare: Southern African Research and Documentation Centre.

[24]. United Cities Local Government (UCLG) (2004). 'Participating Women Elected Representatives in the World' (www.citieslocalgovernments.org/uclg). Accessed 23 November 2010.

[25]. Ziyambi, N (1997). 'The Battle of the Minds: International New Media Elements of the New Religious-Political Right in Zimbabwe'. M. Phil Thesis. University of Oslo: Oslo. 